Gomez, S., Huynh, R., Arroyo, P., Ballard, G., Tommelein, I.D. and Tillmann, P., (2019). “Changing Behaviors Upstream to Achieve Expected Outcomes." In: Proc. 27 th Annual Conference of the International. Group for Lean Construction (IGLC), Pasquire C. and Hamzeh F.R. (ed.), Dublin, Ireland, pp. 13-24. DOI: https://doi.org/10.24928/2019/0216. Available at: <www.iglc.net>.

\title{
CHANGING BEHAVIORS UPSTREAM TO ACHIEVE EXPECTED OUTCOMES
}

\author{
Sulyn Gomez ${ }^{1}$, Raymond Huynh², Paz Arroyo ${ }^{3}$, Glenn Ballard ${ }^{4}$, Iris Tommelein ${ }^{5}$, \\ and Patricia Tillmann 6
}

\begin{abstract}
A behavior-based approach to quality has been proposed to highlight the impact that upstream behaviors have on the overall outcomes of construction projects. The focus of this pioneering approach is first to understand that certain behaviors lead to conversations in which expectations are clearly identified and understood by the different project participants, and then to set measurable acceptance criteria so that the final result can be compared with what was agreed. Previous research has described the approach and provided positive results in satisfying client's expectations, but the process to achieve such outcomes has not been captured. This paper captures the implementation of this behavior-based quality (BBQ) approach to quality management, that has as its main goal to have no surprises, zero rework, and to improve delivery of value to all the project participants engaged at any point of a construction project. Construction projects are to be planned first for quality to fully understand expectations of what the team should build, then for safety to identify any potential risks associated with the processes to build the agreed work and define how tasks will be built in a safe manner, and then for production to secure flow and an adequate use of resources.
\end{abstract}

\section{KEYWORDS}

Quality, behavior-based quality (BBQ), behavior, distinguishing features of work (DFOW), measurable acceptance criteria (MAC).

\section{INTRODUCTION}

Many definitions have been suggested for quality; for example, Crosby's (1979 p. 7) wrote "the first erroneous assumption is that quality means goodness, or luxury, or shininess, or weight." Deming (1982) also defined it as "a predictable degree of uniformity and dependability at low cost and suited to the market", whereas the American Society for Quality (ASQ 2018) defined it as "a subjective term for which

1 PhD Student, Civil and Environmental Engineering Department, University of California, Berkeley, CA 94720-1712, USA, +1 765 775-6583, sulyn@ berkeley.edu

2 Senior Project Engineer, Quality Champion, DPR Construction, San Francisco, CA 94111, USA, +1 415 528-1045, rhuynh28@gmail.com

3 Quality Leader, Quality Corporate Team, DPR Construction, San Francisco, CA 94111, USA, +1 510 520-6238,paza@dpr.com

4 Research Director, Civil and Envir. Engrg. Dept., Project Production Systems Lab., Univ. of California, Berkeley, CA 94720-1712, USA, +1 415 710-5531, gballard@ berkeley.edu

5 Professor, Civil and Envir. Engrg. Dept., Director of the Project Production Systems Lab., Univ. of California, Berkeley, CA 94720-1712, USA, +1 510 643-8678, tommelein@ berkeley.edu

6 Senior Lean Manager, University of California, San Francisco, CA 94103, USA, +1 415 279-9102, patricia.andretillmann@ucsf.edu 
each person or sector has its own definition." Quality has been also understood as meeting the requirements of a well-defined scope of work (Ferguson and Clayton 1988), or meeting the legal, aesthetic, and functional requirements of a project (Arditi and Gunaydin 1997). Researchers have suggested that quality is a major concern worldwide in the construction industry and it needs improvement (Rumane 2011; Arditi and Gunaydin 1997). Winch et al. (1998) highlighted that "A surprised client is a dissatisfied client" and particularly in the construction industry as a service industry, the entire team is responsible for delivering a quality product. For instance, failing in doing so might result in waste and may cause delays and increase the project cost. The Navigant Construction Forum reported that the average rework on projects can cost between $7.25 \%$ and $10.89 \%$ of the total construction cost while potentially impacting the project with a delay of $9.8 \%$ from the original schedule (Dougherty et al. 2012). Different approaches to quality converged with the goal to have a predictable result, which translates in zero rework or no surprises on site (Spencley et al. 2018; Arditi and Gunaydin 1997; Winch et al. 1998; Deming 1982); however, traditional approaches focused on quality control only have been proven to be too reactive as they work once errors are detected (P2SL, 2018), moreover, efforts to assure quality in construction are fragmented and quality is often seen as a concern to field activities only.

Flynn (2001) introduced the concept of behavior-based quality (BBQ) for organizations whose quality has reached a plateau and aim to keep improving by managing upstream behaviors rather than downstream defects. Flynn suggested that behaviors are reinforced by consequences; therefore, in an industry such as construction where quality is a concern, project teams are motivated to behave differently by the desire to obtain different results, by the desire to please their clients, by the desire to achieve some goals or to act in accordance with certain principles. Such understanding was strengthened by Spencley et al. (2018) who introduced the BBQ concept to shift the traditional quality management in construction to increase the likelihood of meeting project participants' expectations with a team that is motivated to think and behave differently. This concept to quality management is also well aligned with Deming's quality principles of eliminating fear from the workplace and fostering a leadership that motivate and encourage workers to participate from processes design (Deming, 1986).

Howell et al. (2017) draw a connection between the lean principle of Respect for People and psychological safety, a term coined by Amy Edmondson (1999). Respect for people requires that each person be helped to develop their capabilities, and this principle supports the organizational objective of continuous learning and improvement. Edmondson establishes a link between feeling safe to speak up, various learning behaviors, and individual and team performance. Another connection to lean construction thinking is between these learning behaviors and reliable promising, and with it the perspective that a project is a network of commitments. Reliable promising can be understood as the basic process underlying $\mathrm{BBQ}$, and the underlying behaviors can be understood as those enabled by psychological safety; namely, to speak truth to power, to feel free to ask questions and make suggestions and ask for help, and to be confident that mistakes you make will be met not with punishment but with help. While reliable promising has been recognized as a critical element in planning and coordination, its application is much broader, and includes situations in which one or more people are responsible for providing something to someone else. Clarification and alignment of customer and provider is the first step in reliable promising, and 
commitment is only made if there is thoughtful consideration of capability to deliver on that commitment. In the context of behavior-based quality, that involves identifying so-called Distinguishing Features of Work (DFOW) (Answering to the question, what do you really want?), developing methods for delivering those features, and having agreement on how to measure whether the features have indeed been delivered.

Construction projects tend to move fast, and information constantly changes. Achieving quality is not a one-time conversation but rather a series of conversations between members to make sure all stakeholders involved in a specific scope of work are aligned around the same expectations, and processes are set in place accordingly to steer towards successfully meeting such expectations. Quality plans are documents that "specify quality standards, practices, resources, specifications, and the sequence of activities relevant to a particular product, service, project, or contract" (ASQ 2018). Such documents contain dense and valuable information about processes and expectations, which might not be easily understood by the trades building the work or it might limit their understanding. Moreover, Willar (2016) included a clear example in which quality plans are prepared solely to satisfy tendering processes. When quality plans are not created for a project-specific case, a misunderstanding of expectations can inevitably create misalignment at early stages. Therefore, finding a way to deliver quality expectations and ensure its compliance on a specific project is required. This paper documents and offers a description of the adoption and implementation process of BBQ in construction practice and the approach followed to foster desired behaviors.

\section{RESEARCH DESIGN}

Lewin (1946) and Somekh (2005) suggested that action research help to test and refine a concept or a process through the application of a set of improvements. This paper describes the first phase of an extensive research effort that applies an action research methodology. The authors seek to understand why and how the BBQ approach works in construction projects and what adjustments in the implementation process are needed for a successful implementation. The cycles of action research used in the study are presented in a step by step process (Fig. 1). In practice this process is not linear. Instead it involves a series of iterations of behaviors, constant interaction, and conversations in which the authors set the different steps to implement the BBQ concept.

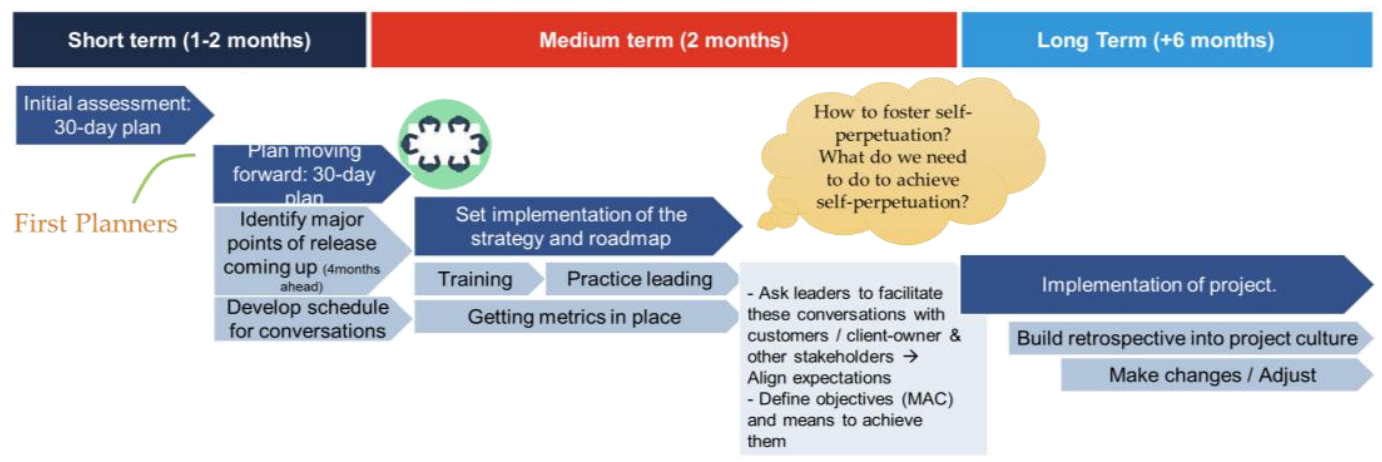

Figure 1: Research Design to Capture BBQ Implementation Process

At the time the paper was written, the authors completed the first iteration of the action research which took about 8 months. Every cycle includes an initial assessment of the current state, plan to identify major points of release, implementation process which 
included training and practice of the BBQ approach to increase awareness and foster self-perpetuation.

\section{Project Description}

The project studied is a 6-story building which program includes three levels of patient treatment clinics, two levels of wet and dry research space and a vivarium. This building will be the centerpiece of the University of California, San Francisco - Mission Bay Campus. The project is being delivered on a fast-tracked schedule by an integrated team with SmithGroup and MCA as architects, DPR as the general contractor, and a donor's representative who acts as a liaison for the project team and the donor. At the time the study was documented, the design was still in development. This made it possible for the project team engaged in early phases and use BBQ implementation to define the project details included in drawings and specifications for construction.

\section{KEY CONCEPTS}

The authors offer their understanding of a set of concepts that facilitate comprehension of the entire implementation framework described in this paper:

\section{Quality}

A work or product is said to meet quality requirements when it meets the expectations agreed by the stakeholders. Expectations, if well defined, can be aligned.

\section{Points of Release}

A point when the work is released (Christian, 2012) or when the next hand off happens. e.g., material purchase, prefabrication, construction, commissioning, turnover, etc.

\section{Distinguishing Features of Work (DFOW)}

DFOWs are the cornerstone of the behavior-based approach to quality. DFOW are the outcomes that each project participant values the most and those areas that the team agrees require increased attention to achieve the intended results. Identifying DFOWs help the project team to pay attention to areas where problems arose in the past, areas that are unique, or there is not shared understanding of what success looks like.

\section{Measurable Acceptance Criteria (MAC)}

MAC is an objective way to evaluate a deliverable. By agreeing on MAC, the team increase the likelihood that the job will be done correctly the first time. Defining the MAC allows the team to evaluate the work before releasing it to the next phase.

- Prescriptive criteria: Consist on testing and inspecting to verify that the product meets the requirements included in drawings and specifications.

- Descriptive criteria: Objective criteria that describe and measure the finish/craftsmanship elements of a product.

\section{RESEARCH FINDINGS}

\section{AWARENESS OF THE NEW APPROACH}

The initial assessment of the project was done when the superstructure construction started on site. In this phase, the project team awareness of the BBQ approach that drives project participants consensus on what quality means upstream was identified as 
a potential area for improvement. Different trades were asked about their involvement in the new approach to achieve quality, what the role of the quality champion was and what their own role was on achieving a quality product. When project participants from different companies were asked who was responsible for quality on the project, most answers put most or all the responsibility of quality on the quality champion. However, the concept of the BBQ approach sees the quality champion as a facilitator who guides the implementation of the approach in workgroups.

The corporate quality team along with the project leaders worked on increasing awareness and educating the project team on a BBQ approach in which the facilitators communicated the purpose for shifting to a different approach. During the first training sessions, expectations for each member of the project team were set clearly. The first phase of the research included increasing awareness from the GC's side. Participants attending the training were expected to take the lead and promote the BBQ approach and engage other trades in the process. Additionally, cause mapping sessions were used on site with GC's team to get their engagement as they identified that some causes for failure were linked to misalignment of project participants' expectations. Habits and behaviors developed in the implementation process are described later in this paper.

\section{HOW BBQ IS DIFFERENT FROM A TRADITIONAL APPROACH}

In a traditional project setting, plans and specifications are often issued to contractors with the assumption that they clearly indicate stakeholder expectations for project outcomes. This misalignment of expectations creates challenges for the contractors during construction because they often build based on a limited understanding of the client's expectations. A consequence is to find defective work once elements of the project are built, which results in a long punch list process for the contractor. Table 1 summarizes the authors' understanding of key differences between traditional quality approaches and the BBQ approach implemented on the project.

Table 1: Traditional Quality Approach Versus Behavior-Based Quality Approach

\begin{tabular}{|c|c|}
\hline Traditional Quality Approach & Behavior Based-Approach (BBQ) \\
\hline Build it - Check it & Seek stakeholders understanding \\
\hline $\begin{array}{l}\text { Stakeholders are not confident to speak } \\
\text { up or raise concerns }\end{array}$ & $\begin{array}{l}\text { Foster psychological safety so people can } \\
\text { speak up and expectations are uncovered }\end{array}$ \\
\hline Culture of knowing / assuming & $\begin{array}{l}\text { Culture of learning \& asking questions / seek } \\
\text { alignment amongst project participants }\end{array}$ \\
\hline Quality is responsibility of one person & $\begin{array}{l}\text { Quality is my responsibility (every person is } \\
\text { responsible to deliver a quality product) }\end{array}$ \\
\hline Blame others when mistakes happen & $\begin{array}{l}\text { Encourage people to speak up \& use cause } \\
\text { mapping }\end{array}$ \\
\hline Unclear/missing communication details & $\begin{array}{l}\text { Quality needs clear language and } \\
\text { transparent/documented agreements }\end{array}$ \\
\hline $\begin{array}{c}\text { Workers are not involved in process } \\
\text { design }\end{array}$ & $\begin{array}{l}\text { Workers feel free and are encourage to } \\
\text { actively participate in processes design }\end{array}$ \\
\hline $\begin{array}{l}\text { Fragmentation and miscommunication } \\
\text { between design and construction }\end{array}$ & $\begin{array}{l}\text { Foster communication and alignment between } \\
\text { points of release }\end{array}$ \\
\hline
\end{tabular}




\section{IMPLEMENTATION PROCESS}

At the onset of the project, the client engaged all key project participants (design leads, general contractor, donor, and users) to define the project's goals. The contractor, understanding the challenges of constructing such a complex building engaged them in a series of meetings to break down specific distinguishing features of the project.

\section{Mapping out Points of Release}

Architectural concrete is a major feature for the project since most shear walls were designed to be exposed concrete. Whereas regular structural concrete is largely specified by ACI standards (ACI, 2019), architectural concrete is specified differently in only one section out of over one hundred listed under topics in concrete by ACI. Due to unfamiliarity, the team realized the scope of work of architectural concrete required DFOW development in detail. In practice, the team used construction milestones from the project schedule to determine the last responsible moment for developing DFOWs and reaching agreement around acceptance criteria. Because of the lack of industry guidelines and a limited understanding of the team in the topic of concrete construction in architectural applications, the team agreed that a mock-up would be the best method for establishing the acceptance criteria. The procurement of the form finish panels was identified as the major point of release and the procurement of the formwork was the driver for completing the mockup and agreeing upon acceptance criteria.

\section{Understanding Expectations}

The list of DFOW grow the closer the project gets to construction. The goal is to better understand design intent and how to realize that intent. The team was challenged to build the architectural shear walls and meet high expectations with a set of specifications that needed further development to be clearly defined. The initial specifications of architectural concrete stated as a requirement to have concrete finishes that were "Interior surface: smooth, mirror-like concrete." Since the scope of work required clarity, the quality champion facilitated a series of conversations with the project participants involved in this scope and guided the team by asking a series of questions to better understand expectations for the surface finish, color, location of form joints, and construction tolerances for the architecturally exposed concrete. The responses to these questions were identified as DFOWs and were put on a list that was reviewed by all the project participants involved. As conversations took place, the design team provided tours and examples of concrete with smooth, matte finishes, making their expectations clearer.

In the case of architectural shear walls, the team started by asking themselves what was distinguishing about that scope of work; was it the forms and how they are placed together? Whether the finishes end up clean and neat after removing forms without an extra pass to clean them? If the wall was plumb? are the joints clean so that it won't affect the final finish of the surface of the concrete? The quality champion facilitated the process through the course of 4 months with the structural engineer, concrete superintendent, the architect, the owner, and the donor's representative. The concrete subcontractor referenced industry standard such as ACI 309R-5 - "Guide for consolidation" and ACI 347.3R-13 - "Guide for Formed Concrete Surfaces" to educate the project participants about materials, means and methods that could be used to meet expectations. This step of the process required the leadership of the team creating the vision and defining a path forward for developing success measures. 
For the donor's representative in the project, the fact that the process included all the project participants that had relation with a DFOW added value to all; however, she recommended that the process itself needs to be explained to all new people coming in the project or otherwise the process might be watered down for having people not aware of it or not up to speed. Also, she said "sometimes we do not communicate well our priorities to the people building the projects". Even though the process can potentially work, the team cannot rely on it completely if people have not understood it properly and a proper communication is in placed between all project participants.

From the architect's point of view, even though understanding the BBQ process was a little hard at the beginning, going thought the process and having the appropriate project participants onboard to discuss DFOW details was key for the success of the scope of work. He said, "the process helped the team to express what was the intent in the documents to avoid confusion and prevent rework ... we're also using a common vocabulary so that everyone can speak the same language."

\section{Getting Team Alignment}

The quality champion engaged the team in several conversations to identify DFOWs and to get agreement on how success was defined. The team achieved great results as they worked together ensuring that construction documents reflect what the real expectations were. The concrete subcontractor felt a great commitment with the plan and they were committed to achieve it. The team held weekly meetings for 4 months to breakdown each DFOW to the level of detail that they needed and verify that every detail they agreed on also satisfy compliance with industry standards guidelines in the ACI. Aligning the team on expectations is a constant action that the team got committed to developing throughout the project duration. To the architect, the clearest illustration of how behaviors were shown in the process was having all team members in the meetings where DFOWs were discussed. From the donor's representative, the behaviors that showed commitment from the team was having the concrete sub trying to understand what the client wanted and bringing alternatives to the table for every DFOW conversation, flashing out any discrepancy that could have come later.

The concrete subcontractor along with the quality champion and the architect also did field trips to other projects in which the architect showed the subcontractor examples of acceptable exposed concrete work. Later conversations helped the team define what in reality the architects wanted, what the GC can provide according to standards, and then as a team defined what is quality for the project. Together, the team worked on defining the color and texture, reveals, form ties, and construction joint details because of the impact on the final product.

\section{Agreeing on Measurable Acceptance Criteria (MAC)}

After the list of DFOWs was created in parallel with the research initial assessment, the team scheduled weekly meetings, leading up to the point of release for procuring the form finish panels. Each week, the subcontractor and GC would search industry standard, means, methods and tolerances for mix designs, formwork materials, vibration and review process and provide measurable solutions for each feature. Once all the project participants agreed upon the acceptance criteria, the concrete subcontractor produced a shop drawing clearly depicting each DFOW and acceptance criteria and requested that the design team revise contract documents to match accordingly. Through this process, the team was able to develop and agree upon 
objective criteria for architectural concrete and increased the likelihood that the scope would be built free of defects and meet expectations. Figure 2 shows a piece of the DFOWs list and measurable acceptance criteria that all the stakeholders agreed for the scope of work of architectural shear walls.

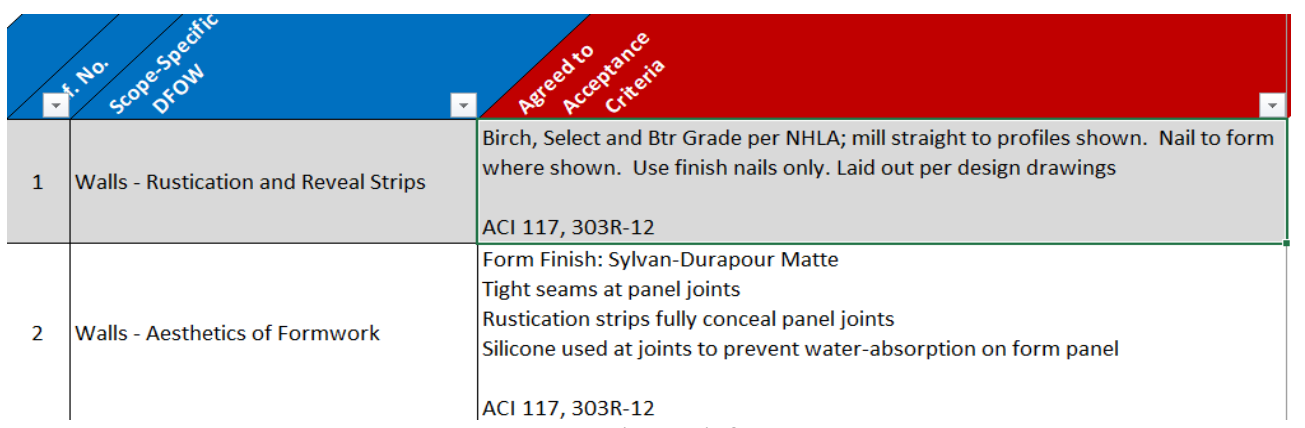

Figure 2: List of DFOW's Developed for Architectural Shear Walls

\section{Execution and Alignment in The Field}

The team achieved to have a set of deliverables that were built as the team agreed on the process. Prior to building the shear walls mock-up and first in place installation, the team developed a detailed plan with means and methods to build architectural shear walls showing all DFOW related to the scope. Other key points from the BBQ that the authors noticed throughout the implementation process are:

- Training and Awareness: Training sessions were developed for the GC's staff to increase awareness of the process. Similarly, field workers were involved during mock-up building to ensure they understood the process and expectations. Training for trade partners and field workers is to be developed in the second phase of the study. The donor's representative said, “you won't create positive behaviors if people don't know what they are supposed to do - that goes back to communication and understanding that we're talking about the same thing."

- Team Commitment and Engagement: The team agreed on being flexible to modify specifications; for example, different quantities of slag were tested in the mock-ups because it affected the color of the concrete. The structural engineer helped to specify maximum allowable slag content that would still provide the concrete strength required for the project. The concrete superintendent also realized that the form release agent and spray cure would affect the finish color, so for each full-scale mockup they did half and half sections with and without form release agent and spray cure. Given the misalignment in the formwork finish (mirror-like vs matte), the team also agreed to build each of the three mockups with different form-facing materials (gloss, matte, and HDO). The project team had developed detailed DFOW for architectural concrete, terrazzo, stone flooring, etc.

- Psychological safety: The architect highlighted that field workers from the concrete crew were also confident and engaged in the process because when problems arise, they pull down the red cord and ask for help stopping the construction process until the they get clarity on any issue that they were concern about. He stated, "I think the conversations we had have created an environment where it feels safe and you can walk through the project anytime without workers feeling pressure." 
- Visual Aids: While building on site, visual aids were placed out in the field to be accessible for field workers and help them be ready for execution. After the concrete was in place, the concrete project engineer measured the final product against the MAC agreed. The DFOW's were also identified on pre-pour checklists so that the foreman signing off each section before a concrete pour could continuously identify whether they were built correctly. Figure 3 shows a piece of the drawing with means and methods diagrams that the teams agreed to move forward with based on the DFOW's. The plans on site show pour sequences, specific vibration patterns, and specific durations for these processes.

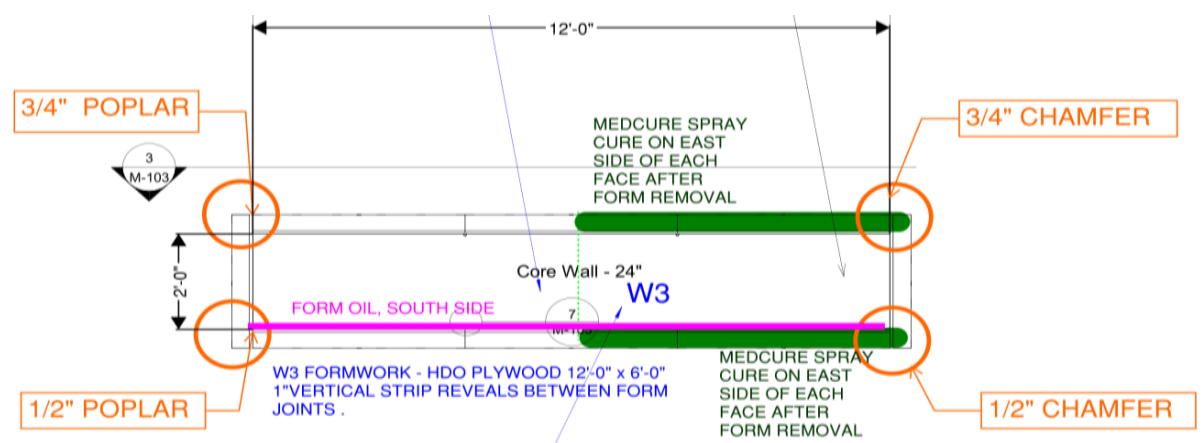

Figure 3: DFOW's Identified for Architectural Shear Walls for the Field

- Transparency and tracking of commitments: Everyone in the job has access to the information about DFOWs developed. The team also made sure that the client understood and approved any potential impact on cost and schedule that might be tied to the process. For example, the higher quality formwork had schedule and cost impacts, so the team discussed the impact with the project participants and allowed the team to make the right decision for the project. The team also created a DFOW log (Fig. 4) to track commitments. As an awareness indicator, the team plan to track whether the team kick off all conversations that they were supposed to. Other meaningful quantifications to measure on the process is how many of the plans in which DFOW were identified were also well-executed.

\begin{tabular}{|c|c|c|c|c|c|c|c|}
\hline \multicolumn{8}{|c|}{ Upcoming/Scheduled DFOW Meetings } \\
\hline \multirow[b]{2}{*}{ Scope } & & & & & & & \\
\hline & $\begin{array}{l}\text { Bid } \\
\text { Package }\end{array}$ & DPR Lead & $\begin{array}{l}\text { DFOW's } \\
\text { Required By }\end{array}$ & $\begin{array}{l}\text { Scheduled } \\
\text { DFOW Meeting }\end{array}$ & Status & Driver & Notes \\
\hline Lab Casework & N/A & Randy Q. & $11 / 30 / 2018$ & $1 / 24 / 2019$ & DFOW developed & Mock-up & $\begin{array}{l}\text { Team to continue DFOW } \\
\text { discussion at Equipment } \\
\text { Cluster on } 1 / 24\end{array}$ \\
\hline Tile \& Stone & 26 & John 0. & $12 / 13 / 2018$ & $71 / 28 / 2018$ & DFOW issued for buyout & Buyout & $\begin{array}{l}\text { DFOW issued 11/29. Pre- } \\
\text { bid RFIs issued to SG } \\
12 / 18\end{array}$ \\
\hline
\end{tabular}

Figure 4: Statusing of DFOW Distributed Weekly to the Project Team

\section{CONCLUSIONS}

The outcome of this study is considered significant to practitioners as it provides a detailed description of the implementation of a behavior-based approach to quality in a construction project. The need to set short-term and long-term plans to be achieved throughout the implementation was identified in the initial research assessment. Shortterm plans included tying points of release to the master schedule and developing pull plans to identify when conversations need to happen. The authors found the need to also set clear expectations from all team members at the beginning of the process, e.g., 
project engineers leading a scope of work were expected to lead the DFOWs conversations for such scope. As when implementing any new approach, educating and training plays an important role in the sustainable implementation. Long-term plans included training and learning from the basic initiatives, e.g., building team alignment and cause mapping whenever disruptions occur. Initiatives such as forums or lunchand-learn sessions are recommended to share knowledge in a project basis. Aiming to build great builders faster, identifying a catalyst to accelerate the dissemination of the BBQ approach is key in the process: a quality champion could facilitate the process and give the ownership of each DFOW conversation to team members that lead the corresponding scope of work.

The behaviors that were identified in this phase of the study are summarized in three principles, acting in accordance with these principles creates the behaviors that support the BBQ approach: (1) "Ask questions constantly.” Most specifications are generic, and they may not even apply to your project. Therefore, it is important to keep asking questions to better define the scope of work. Only if you ask questions such as what is important for you about this scope will lead to identifying DFOWs. Keep reminding people that if the team does not follow this process, there will be surprises and we will make the same mistakes we did in the past. BBQ has been recognized as a process worth doing, as per the quality champion said: "Some people were asking why we were doing this so early on, and why the architects are not just giving answers... This (process) fundamentally changes the way we build and how we see the end-product. Yes, we will disagree at the beginning, but if we go through this process we increase the likelihood that there will not be any surprises at the end of the day." (2) "Overcome resistance." Implementing the process is hard work and you will get resistance, but it is worth doing. Benefits of implementing this approach are: avoiding a massive amount of rework, building trust among project participants, and getting the right quality for the project. The process itself helped build the team. The concrete subcontractor bought the idea and benefits of the process and expressed his thoughts as: "I would highly recommend this (process) for any project that has some ambiguity in their designs and specs. This is the first time I did this on a job, and I would do this for every job." (3) "Trust and empower your team." It was important to let the project engineers and superintendent in charge of managing a specific scope to lead kickoff meetings in which they explain the process to subcontractors and lead them throughout the implementation. The team should work together to verify that documents are timely, appropriately complete, and have captured the team's expectations. A very clear procedure communicated in the field is required to achieve expected outcomes.

\section{FUTURE RESEARCH}

The authors aim to define a process for behavior-based quality approach to construction projects, capture challenges when it is implemented, and refine the process accordingly.

\section{ACKNOWLEDGMENTS}

Development of the ideas presented in this paper was supported in part by gifts made to the Project Production Systems Laboratory (P2SL). All support is gratefully acknowledged. Any opinions, findings, conclusions, or recommendations expressed in this paper are those of the authors and do not necessarily reflect those of contributors to P2SL. 


\section{REFERENCES}

American Concrete Institute (2019). "ACI: Topics in Concrete." https://www.concrete.org/topicsinconcrete.aspx (Feb. 22, 2019).

American Society for Quality (2008). "ASQ Glossary." < https://asq.org/qualityresources/quality-glossary> (Feb. 22, 2019).

Arditi, D., and Gunaydin, H.M. (1997). "Total Quality Management in the Construction Process." International J. of Project Management, 15(4), 235-243.

Chandrupatla, T.R. (2009). Quality and Reliability in Engineering. Vol. 2., Cambridge University Press (NY), New York.

Christian, D. (2012). "Where Ambitious Owners with Ambitious Projects Need Ambitious GC's to Focus." Unpub. Presentation, DPR Quarterly Mtg., April 25.

Crosby, P.B. (1979). Quality is Free: The Art of Making Quality Certain. McGraw-Hill (NY), New York, p. 7.

Deming, W.E. (1982). Quality, Productivity and Competitive Position. MIT, Cambridge, MA, UK, pp. 373

Deming, W. E. (1986). Out of the Crisis. MIT Press., Cambridge, MA, UK, pp. 524.

Dougherty, J.M., Hughes, N., and Zack, Jr., J.G. (2012). "The Impact of Rework on Construction and Some Practical Remedies." Navigant Construction Forum, Navigant, 21.

Edmondson, A. (1999). "Psychological Safety and Learning Behavior in Work Teams." Administrative Science Quarterly, 44(2), 350-383.

Ferguson, H. and Clayton, L. (1988). Quality in the Constructed Project: A Guideline for Owners, Designers and Constructors. ASCE, Vol 1., New York.

Flynn, K. (2001). "Behavior-Based Quality - Connecting People to the Systems." Behavioral Science Technology Annual Spring Conf. Proc., Chicago, IL.

Howell, G., Ballard, G., and Demirkesen, S. (2017). "Why Lean Projects are Safer." Proc. 25 ${ }^{\text {th }}$ Ann. Conf. Int'l. Group for Lean Constr., Heraklion, Greece, pp. 4-12.

Lewin, K. (1946). "Action Research and Minority Problems.” J. of Social Issues, 2(4), 34-46.

Rumane, A.R. (2011). "Quality Management in Construction Projects." ASCE, Construction Research Congress, Boca Raton, FL.

Somekh, B. (2005). Action Research: A Methodology for Change and Development. McGraw-Hill Education (UK).

Spencley, R., Pfeffer, G., Gordon, E., Hain, F., Reed, D., and Marosszeky, M. (2018). "Behavior-Based Quality Closing the Knowing Doing Gap." Proc. $26^{\text {th }}$ Ann. Conf. Int'l. Group for Lean Construction (IGLC 26), Chennai, India, 1170-1181.

Willar, D. (2016). "Developing Attributes for Evaluating Construction Project-Based Performance." The Total Quality Management Journal, 29(2), 369-384.

Winch, G., Usmani, A., and Edkins, A. (1998). "Towards Total Project Quality: A Gap Analysis Approach." Construction Management and Economics, 16(2), 193-207. 
Gomez, S., Huynh, R., Arroyo, P., Ballard, G., Tommelein, I.D. and Tillmann, P. 